\title{
Molecular Diversity Assessment Using Sequence Related Amplified Polymorphism (SRAP) Markers in Vicia faba $\mathrm{L}$.
}

\author{
Salem S. Alghamdi ${ }^{1{ }^{*}}$, Sulieman A. Al-Faifi ${ }^{1,2}$, Hussein M. Migdadi ${ }^{1}$, Muhammad Altaf Khan ${ }^{1}$, \\ Ehab H. EL-Harty ${ }^{1}$ and Megahed H. Ammar ${ }^{1}$
}

1 Legume Research Group, Plant production Department, Collage of Food and Agricultural Sciences, King Saud University, P.O. Box 2460, Riyadh 11451, Saudi Arabia; E-Mails: salfaifi@ksu.edu.sa (S.A.F.); h.migdadi@gmail.com (H.M.M.); altaf_sbs@yahoo.com (M.A.K.); ehabelharty@gmail.com (E.H.H.); ammarrice@gmail.com (M.H.A.)

2 College of science and humanity studies, Salman Ibn Abdulaziz University, P.O. Box 83, Alkharj 11492, Saudi Arabia

* Author to whom correspondence should be addressed; E-Mail: salem@ksu.edu.sa; Tel.: +966-1-4678344; Fax: +966-1-4678466.

Received: 2 October 2012; in revised form: 9 November 2012 / Accepted: 12 November 2012 / Published: 4 December 2012

Abstract: Sequence-related amplified polymorphism (SRAP) markers were used to assess the genetic diversity and relationship among 58 faba bean (Vicia faba L.) genotypes. Fourteen SRAP primer combinations amplified a total of 1036 differently sized well-resolved peaks (fragments), of which all were polymorphic with a 0.96 PIC value and discriminated all of the 58 faba bean genotypes. An average pairwise similarity of $21 \%$ was revealed among the genotypes ranging from $2 \%$ to $65 \%$. At a similarity of $28 \%$, UPGMA clustered the genotypes into three main groups comprising $78 \%$ of the genotypes. The local landraces and most of the Egyptian genotypes in addition to the Sudan genotypes were grouped in the first main cluster. The advanced breeding lines were scattered in the second and third main clusters with breeding lines from the ICARDA and genotypes introduced from Egypt. At a similarity of $47 \%$, all the genotypes formed separated clusters with the exceptions of Hassawi 1 and Hassawi 2. Group analysis of the genotypes according to their geographic origin and type showed that the landraces were grouped according to their origin, while others were grouped according to their seed type. To our knowledge, this is the first application of SRAP markers for the assessment of genetic diversity in faba bean. Such information will be useful to determine optimal breeding 
strategies to allow continued progress in faba bean breeding.

Keywords: Vicia faba L.; genetic diversity; germplasm collection; SRAP markers

\section{Introduction}

Faba bean ( $2 n=2 x=12$ chromosomes) is characterized by its larger and more complex genome compared with other legumes. Its size of 13,000 $\mathrm{Mb}$ [1] is more than 10 times the size of soybean (Glycine max) (1200 Mb), four times the size of pea (Pisum sativum) (4000 Mb), and 29 times the size of alfalfa (Medicago sativa) (450 Mb) [2]. Due to the genome complexity, relatively little progress has been made in faba bean breeding for elite cultivars that can withstand adverse environmental conditions. Using molecular markers to assess genetic diversity is important not only for crop improvement efforts, but also for efficient management and conservation of plant genetic resources in genebanks. Several molecular markers have been used in the characterization of genetic diversity, gene tagging, and mapping of important genes in faba bean [3-7].

The genetic diversity of faba bean has been studied with a number of molecular marker systems, including restriction fragment length polymorphism (RFLP) [8,9] random amplified polymorphic DNA (RAPD) [9,10], amplified fragment length polymorphism (AFLP) [5,11,12], inter simple sequence repeats (ISSRs) [13,14], genomic microsatellites (SSRs) [15], and target region amplification polymorphism (TRAP) [16]. Molecular markers were used to study the taxonomic relationships between closely related species of Vicia faba L. by RFLP- and PCR-generated data [17] as well as analyze mitochondrial and chloroplast DNA [18-20]. In a previous study, long terminal repeat sequence retrotransposon based markers were compared for their usefulness in sequence specific amplified polymorphism (SSAP) marker development in two Vicia species ( $V$. narbonensis and $V$. faba L.), which had distinguished between geographic origins of $V$. faba L. genotypes, but not between minor or major types [21].

Sequence-related amplified polymorphism (SRAP) is a simple and efficient molecular marker technique, reasonable throughput rate, disclosure of numerous co-dominant markers, ease of isolation of bands for sequencing, more reproducible than RAPDs and are easier to assay than AFLPs and, most importantly, targeting of open reading frames (ORFs) [22]. It has been used for genetic diversity and phylogenetic studies in different legume crops: lentil [23], alfalfa [24-26], pea [27]. The exploration of genetic diversity and the relationships among conserved faba bean germplasm collections is essential and of critical importance in establishing, managing, and ensuring the long-term success of faba bean breeding programs.

The aim of this study was to evaluate the potential of SRAP markers for assessing genetic relationships and diversity in faba bean germplasm collections. To our knowledge, this is the first application of SRAP markers for the assessment of genetic diversity among faba bean collections. 


\section{Results}

A total of 55 different SRAP primer combinations using five forward and eleven reverse primers were evaluated for their ability to prime PCR amplification of eight randomly selected genotypes. Only fourteen primer combinations which showed consistently reproducible polymorphisms were selected and used to analyze all of the 58 faba genotypes. The features of the primers across all 58 genotypes tested are summarized in Table 1 .

Table 1. The features of Sequence-related amplified polymorphism (SRAP) primers selected in faba bean genetic diversity.

\begin{tabular}{ccccc}
\hline Primer combination & $\begin{array}{c}\text { Total } \\
\text { fragments }\end{array}$ & $\begin{array}{c}\text { Average } \\
\text { fragments }\end{array}$ & $\begin{array}{c}\text { Total no. of } \\
\text { fragments }\end{array}$ & PIC value \\
\hline ME1/EM1 & 85 & 18 & 1,047 & 0.97 \\
ME1/EM2 & 158 & 26 & 1,563 & 0.99 \\
ME1/EM3 & 134 & 31 & 1,817 & 0.99 \\
ME1/EM4 & 56 & 11 & 662 & 0.97 \\
ME2/EM1 & 46 & 8 & 444 & 0.95 \\
ME2/EM2 & 108 & 24 & 1,417 & 0.98 \\
ME2/EM4 & 10 & 3 & 190 & 0.84 \\
ME3/EM1 & 77 & 17 & 1,013 & 0.97 \\
ME3/EM2 & 69 & 7 & 414 & 0.97 \\
ME3/EM3 & 66 & 5 & 323 & 0.98 \\
ME3/EM4 & 54 & 10 & 567 & 0.96 \\
ME4/EM2 & 59 & 5 & 323 & 0.97 \\
ME4/EM3 & 16 & 4 & 220 & 0.92 \\
ME4/EM4 & 98 & 12 & 700 & 0.98 \\
Total & 1,036 & - & 10,700 & - \\
Average & 74 & 13 & 764 & 0.96 \\
\hline
\end{tabular}

${ }^{\mathrm{a}}$ Total number of differently sized SRAP fragments amplified across all 58 genotypes; ${ }^{\mathrm{b}}$ Average number of SRAP fragments scored per genotype; ${ }^{\mathrm{c}}$ Total number of SRAP fragments scored for all genotypes.

The 14 primer pairs generated a total of 1036 differently sized well-resolved peaks (fragments), of which all were polymorphic over all of the genotypes. In total, 10,700 data points (amplified fragments) were scored with an average of 764 peaks per primer pair across all genotypes, thereby confirming the high multiplex ratio expected for SRAPs. The capability of different primer pairs to generate SRAP fragments varied significantly, ranging from 10 in primer pair ME2/EM4 to 158 in primer pair ME1/EM2, with an average of 74 fragments per primer pair. The average number of fragments per primer pair ranged from 3 in primer ME2/EM4, to 31 in primer ME1/EM3, with an average of 13 fragments per primer per genotype.

All primer pairs generated 100\% polymorphic fragments (Table 1). The polymorphic information content (PIC), measured as the percentage of polymorphic fragments for all primer pairs was high and varied in a relatively narrow range of $84 \%$ (for primer pair ME2/EM4) to $99 \%$ (for primer pairs ME1/EM2 and ME1/EM3), with an average of $96 \%$. An example of a typical electropherogram representing the pattern of amplified DNA using all 58 faba genotypes with the polymorphic and 
common peaks is presented in Figure 1. Before the genotypes were used in analysis, the sizing quality, bin assignment, and allele calls were reviewed manually for accuracy. The genetic similarity estimates based on the Jaccard similarity coefficients for the SRAP data were used to assess the genetic relatedness among the 58 genotypes. The mean similarity indices presented by the genotypes ranged from 0.02 to 0.66 with an overall genotype similarity of 0.21 .

Figure 1. Electropherograms of three faba samples representing three genotypes using ME1/EM2 primers combination run on the Applied Biosystems 3130xl Genetic Analyzer displayed in the GeneMapper software v3.7 (Applied Biosystems: Foster City, CA, USA). The arrow denotes polymorphic peaks that are present or absent in just one sample.
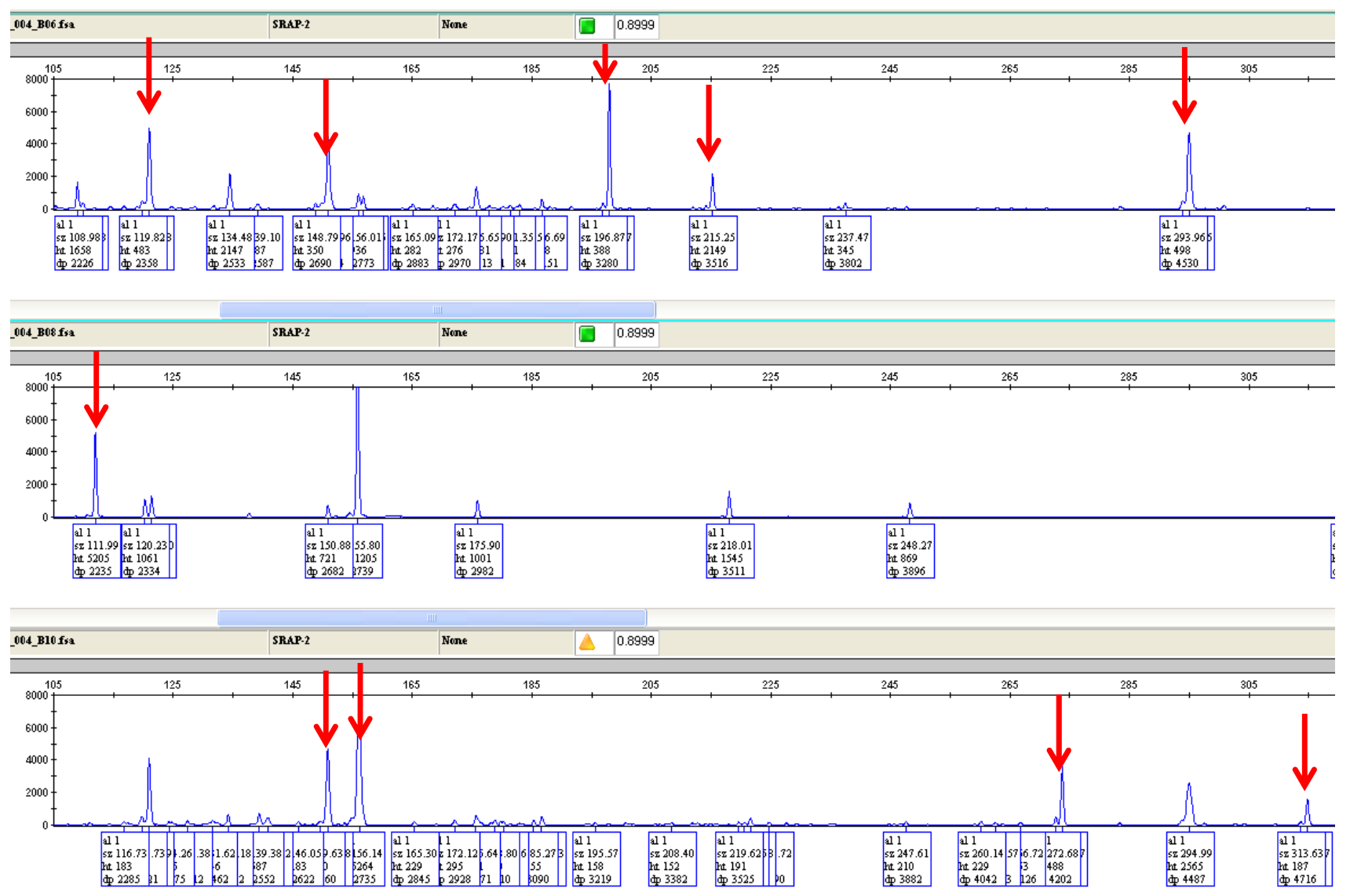

The UPGMA cluster analysis of the genotypes based on the SRAP data was cut at a similarity of 0.28 (which represented $67 \%$ of the distance from the maximum similarity of 0.65 to the minimum of 0.09). Cutting the dendrogram at this similarity value resulted in three main clusters comprising $78 \%$ of the genotypes, two small clusters comprising $6 \%$ of the genotypes, and nine single clusters comprising $16 \%$ of the genotypes (Figure 2). The local genotypes (landraces) and most of the Egyptian genotypes, in addition to the Sudanese genotypes were grouped in the first main cluster with an average genetic similarity among these genotypes of 0.31 . The closest genotypes were Hassawi 1 and Hassawi 2 with similarity index value of 0.65 , while the most diverse genotype in this cluster was Gazira 1 with a 0.22 similarity value to the local genotype Goff 1 (Figure 2).

In the second main cluster, five elite breeding lines (produced from crosses utilizing the land races in the local faba breeding program at the legume research group) grouped with exotic genotypes with 
an average similarity index of 0.29 . The closest genotypes in this cluster were Luz, Yamani (LS), and Pop.6, which had a 0.35 similarity index with Giza blanka, while the most diverse genotype in this cluster was sakha1 which had a 0.20 similarity value with Yamani (LS).

The third main cluster included an additional five advanced breeding lines produced from crosses utilizing the land races and Egyptian genotypes, with an average genetic similarity value 0.32 . The advanced breeding lines (Pop.3 and line 9) were the most closely related with a similarity index value of 0.41 , while Line 5 and Cairo 7 were the most distantly related in this cluster with the lowest similarity value of 0.26 .

Figure 2. Dendrogram produced by Jaccard's coefficient and the unweighted pair group method with arithmetic average (UPGMA) clustering method based on SRAP data in 58 faba bean genotypes.

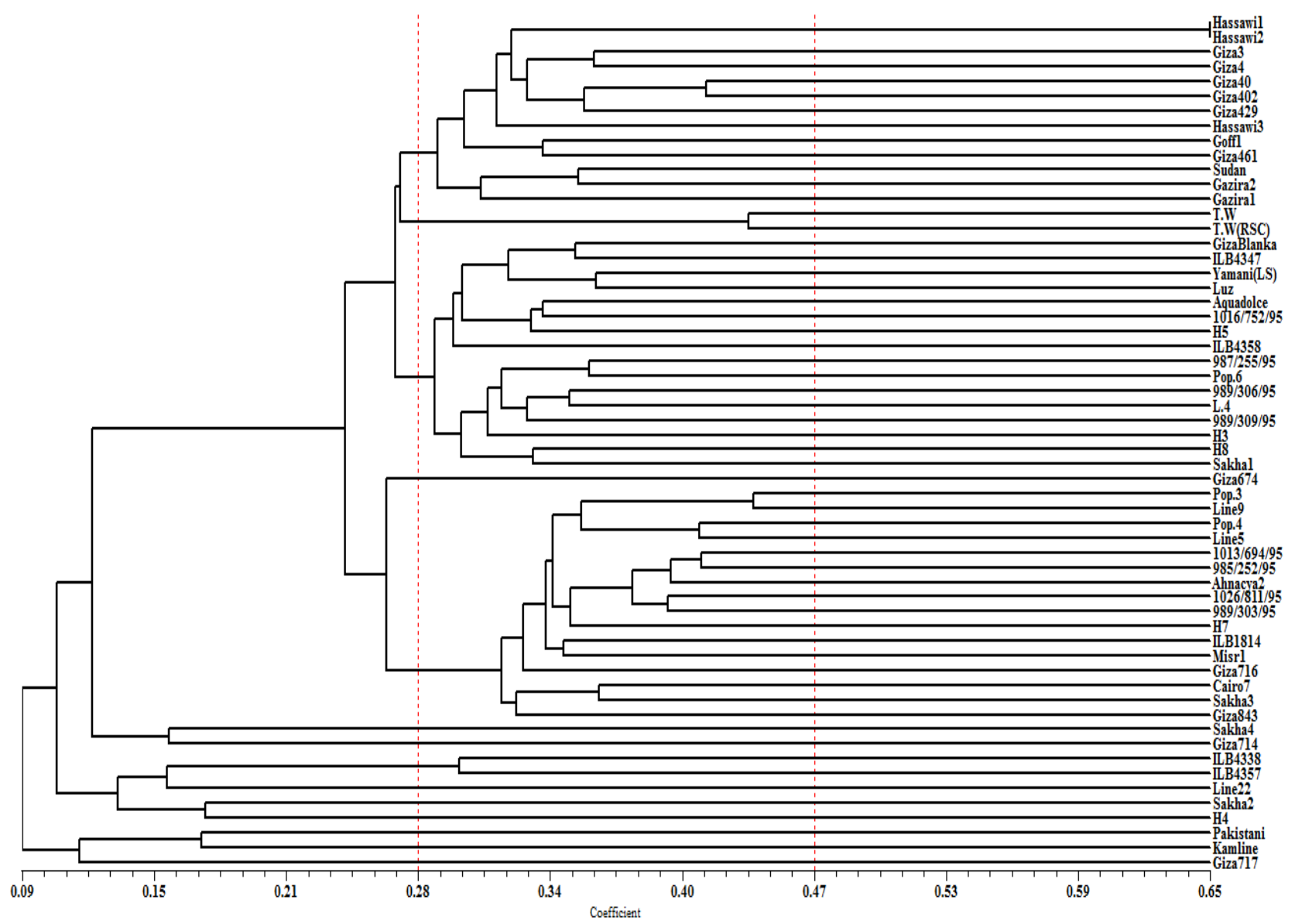

The two small clusters grouped Triple white (T.W) and Triple white (T.W) red seed coat in one cluster, and the two ICARDA's genotypes (ILB4338 and ILB4357) in the second cluster. Nine genotypes formed individual clusters and were considered the most diverse genotypes. The dendrogram was further cut at 0.47 , which represents $33 \%$ of the distance from the maximum similarity of 0.65 to the minimum of 0.09 . Cutting the dendrogram at this similarity resulted in all of the genotypes forming separated clusters, with the exceptions of Hassawi 1 and Hassawi 2. At a similarity index of 0.66 Hassawi 1 and Hassawi 2 were separated to form two single clusters.

Group analysis of the genotypes according to their origin showed that cutting the dendrogram at a similarity value of 0.20 (which represented $25 \%$ of the distance from the maximum similarity of 0.26 
to the minimum of 0.05 ) resulted in two main clusters, with the Pakistani genotype forming a third individual cluster.

The first cluster was further subdivided into two sub clusters. The first sub cluster included local landraces with Sudan genotypes, while the Yamani and Spain genotypes formed the second sub cluster. The national elite breeding lines clustered with breeding materials from ICARDA as well as the Egyptian genotypes, forming the second cluster (Figure 3).

Figure 3. Dendrogram produced by Jaccard's coefficient and the UPGMA clustering method based on SRAP data in eight faba bean genotypes resources.

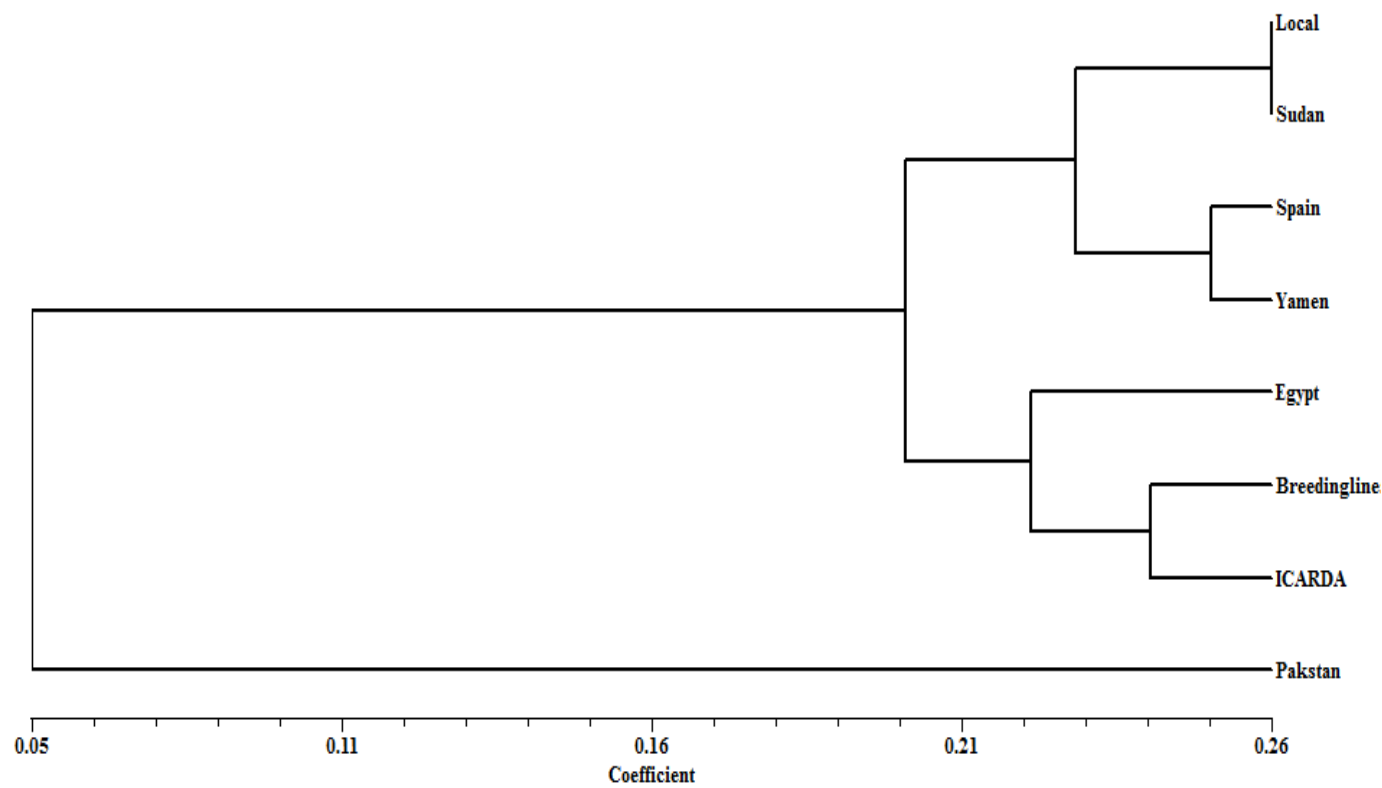

\section{Discussion}

Assessment of the genetic variation within collections of faba bean genetic resources is crucial for the effective conservation and utilization of these resources in breeding programs, and could be dramatically enhanced by using molecular genotyping tools. Genetic variability in faba bean has been previously studied using different DNA molecular markers [3,8,10-16,28-31]. However this is the first application of SRAP markers as a tool for estimating genetic diversity in faba bean.

SRAP is a powerful technique for the assessment of genetic variability because it has shown a high degree of reproducibility and discriminatory power, as well as a high polymorphism rate in many genetic studies. In this study, the number of polymorphic fragments amplified by each primer averaged 74, ranging from 10 to 158 for all genotypes, with a range of 1 to 31 (average of 13) fragments per primer pair per genotype. All primer pairs generated 100\% polymorphic fragments, so the number of fragments and the polymorphism percentages in this study were higher than those obtained in other genetic diversity studies utilizing SRAP markers on other plant species, or on faba bean using different molecular marker approaches [32]. Polymorphism rates and PIC values were used to measure the genetic diversity of faba genotypes in our collection. The average PIC value obtained in this study was 0.96, indicating that all of the SRAP markers showed high polymorphism and could contribute basic information to the genetics and breeding research of faba bean. It was recorded that 50 to 100 markers 
were enough to provide reliable pedigree information [33]. Nevertheless, it was reported that 150 polymorphic alleles were enough to estimate genetic similarities among maize inbred lines [34]. In this study, we analyzed 1,036 polymorphic fragments ranging in size from 100 to $500 \mathrm{bp}$, with an average of 74 fragments per combined primer pair. This was a relatively high number of SRAP markers compared to those obtained in other species [22,24,25,27,35-45], where the presence of 6-44 polymorphic bands per primer combination were reported.

The high polymorphism rate in this study coincides with those obtained in other plant species including $90 \%$ and $96.1 \%$ in alfalfa [24,25], 95\% in buffalograss [36], 89\% in jute [43], 87.59\% in Musa [46], and $95.23 \%$ in Paeonia [47]. However, the polymorphic rate observed in this study was much higher than that generated using SRAP markers in other plant species, including $73.4 \%$ in cassava varieties [48], 56.0\% in eggplant and related Solanum species [49], 47.2\% and 72\% in sesame [39,40], $81.97 \%$ in Pogostemon [50], 49.39\% in Brassica juncea [51], 72.7\% in Cucurbita pepo [52], 66.2\% in Cucurbita moschata [35], 57\% and 76.4\% in safflower [41,42], 43\% in Coffea arabica [45], 50\% in Turkish okra [53], and 83\% in sugarcane germplasm collections [37]. The variation of polymorphism rate reflects the extend of genetic divergence among and within the populations and/or genotypes studied and SRAP combinations used. These findings demonstrate the usefulness of SRAP markers in detecting of genetic variability in various plant species. The precision and accuracy in detecting genetic diversity at a molecular level makes it the marker system of the choice when studying closely related genotypes.

The high polymorphic rate $(100 \%)$ and PIC value $(0.96)$, together with the low genetic similarity (0.21) observed among genotypes in this study suggests a high level of heterogeneity, which is expected for faba bean since they are partially cross-pollinated and are heterogeneous mixtures of inbreds and hybrids, and is a result of outcrossing in faba bean [54-57]. In a previous study which utilized 364 AFLP fragments from five faba bean landraces, intra genetic variation ranged from 0.034 to 0.391 [58].

High levels of intra-population genetic diversity have been observed within the Mediterranean faba bean populations with the aid of ISSRs [13]. It was reported that the Mediterranean-type populations of faba bean are mixtures of Vicia faba L. minor, Vicia faba L. equine, and Vicia faba L. major [59]. This high Level of polymorphism in faba collections has been reported using different molecular markers, including ISSRs [13,14], AFLP markers [5,11,12,58], microsatellite markers [15], and TRAP markers [16]. However, [29] investigated the genetic diversity of faba bean from China and Europe using EST-SSR markers, and the results suggested that the genetic range of faba bean cultivars in China was narrow.

The UPGMA cluster analysis of the genotypes based on the SRAP data illustrated considerable association between the molecular diversity and geographic origin (source) of the genotypes. The local genotypes (landraces) and most of the Egyptian Giza genotypes, in addition to the Sudan genotypes were grouped in the first main cluster. A common feature of these genotypes is that they share a seed type, which is the equine type. Additionally, Hassawi 2 was used as one of the parents in the production of the Gazira 1 and Gazira 2 genotypes. The second cluster encompassed genotypes from Yemen and Spain, which have the Vicia faba L. major seed type. The KSU advanced breeding lines were scattered in the second and third main clusters with breeding lines from the ICARDA and 
genotypes introduced from Egypt, which suggests that these advanced lines were probably developed by utilizing ICARDA and Egyptian faba germplasm.

The T.W and T.W red seed coat were grouped in one small cluster, where T.W red seed coat is a mutant derived from T.W with a different seed coat color. ILB4338 and ILB4357, ICARDA's breeding lines, were grouped in the second small cluster, suggesting that these genotypes could have the same genetic background. The genotypes singled out of these clusters are considered the most diverse genotypes, and they also have distinctive phenotypic traits. The Pakistani genotype is characterized by its dark seed coat color, minor type, and short plant height. The Kamline genotype has a white seed coat color with equine type, and the Sakha 2 genotype has the Vicia faba L. major type seed coat. Furthermore, group analysis of the genotypes according to their geographical origin showed that the Pakistani genotype, which formed an individual cluster, was the most diverse.

Our findings coincide with those of [5], who reported that the Asian faba lines clustered separately from lines from other geographic regions including those from Northern Europe, Southern Europe, and North Africa using AFLP markers. It was also confirmed that faba bean entries collected from within China formed a separate distinct group from faba bean collected from Europe, Africa, and other parts of Asia [11,12]. Our results were in partial agreement with those of [27], which used SRAP markers for characterization of pea accessions, and found no relationship between the origin of the accessions and the morphological and molecular clusters reflecting the exchange of germplasm among breeding programs in different countries.

Our results with SRAP markers suggest that the collection of faba bean cultivars utilized in this study is genetically diverse, in contrary to the results published by [29] who utilized EST-SSR markers. The clustering results of the studied genotypes were largely dependent on seed type rather than geographical origin. The clustering based on seed type is quite logic since major, minor and equine seed types represents the main cultivars groups [60] or even interfertile subspecies in some classification schemes of Vicia faba L. [61]. Thus, the clustering was clearly coherent with genetic constitution rather than origin per se.

\section{Experimental Section}

\subsection{Plant Materials and DNA Extraction}

Two week old faba bean leaves from 58 selected genotypes (Table 2) were collected, dropped in liquid $\mathrm{N}_{2}$, and stored at $-80{ }^{\circ} \mathrm{C}$ until DNA isolation could be performed. DNA isolation was carried out using a modified SDS protocol [62].

The samples were ground in liquid $\mathrm{N}_{2}$ and $200 \mathrm{mg}$ were mixed with $800 \mu \mathrm{L}$ of extraction buffer (100 mM Tris- $\mathrm{HCl} \mathrm{pH} 8,50 \mathrm{mM}$ EDTA $\mathrm{pH} 8,1.4 \mathrm{M} \mathrm{NaCl}, 2 \%$ SDS $v / v$, PVP 2\% $v / v$, and 0.1\% mercaptoethanol), and incubated at $65{ }^{\circ} \mathrm{C}$ for $30 \mathrm{~min}$. Then, $3 \mu \mathrm{L}$ RNase $1(10 \mathrm{mg} / \mathrm{mL})$ was added to each sample and incubated at $37{ }^{\circ} \mathrm{C}$ for $15 \mathrm{~min}$. An equal volume $(100 \mu \mathrm{L})$ of chloroform-isoamyl alcohol 24:1 was added; the samples were mixed well, and centrifuged at 13,680 $\mathrm{g}$ for $20 \mathrm{~min}$. The supernatant was transferred to new $1.5 \mathrm{~mL}$ tubes and a $1 / 3$ volume of $5 \mathrm{M}$ potassium acetate was added. The samples were vigorously mixed, and centrifuged at $13,680 \times g$ for $20 \mathrm{~min}$. The supernatant was removed and transferred to new $1.5 \mathrm{~mL}$ tubes, $1 / 2$ volume of cold isopropanol was added, and the 
samples were mixed well and incubated at $4{ }^{\circ} \mathrm{C}$ for $1 \mathrm{~h}$. The samples were then centrifuged at $13,680 \times g$ for $15 \mathrm{~min}$ at $4{ }^{\circ} \mathrm{C}$. The supernatant was poured off and the tubes were inverted and allowed to air dry for $10 \mathrm{~min}$. The pellets were re-suspended in $300 \mu \mathrm{L}$ of TE (10 mM Tris, $1 \mathrm{mM}$ EDTA, pH 8.0), incubated at $65{ }^{\circ} \mathrm{C}$ for $30 \mathrm{~min}$, and the samples were centrifuged at $13,680 \times \mathrm{g}$ for $5 \mathrm{~min}$ at $4{ }^{\circ} \mathrm{C}$. The supernatants were transferred to new $1.5 \mathrm{~mL}$ microfuge tubes, and $1 / 10$ th volume of $3 \mathrm{M}$ sodium acetate and 2/3rd volume of ice-cold isopropanol were added. The samples were mixed well, incubated at $4{ }^{\circ} \mathrm{C}$ for $1 \mathrm{~h}$, and centrifuged at $13,680 \times g$ for $10 \mathrm{~min}$ at $4{ }^{\circ} \mathrm{C}$ to pellet the DNA. The solution was discarded and the pelts were washed with $80 \% \mathrm{EtOH}$ for $10 \mathrm{~min}$, centrifuged at $13,680 \times \mathrm{g}$ for $10 \mathrm{~min}$ at $4{ }^{\circ} \mathrm{C}$, the solution discarded, and the tubes were inverted to dry for $30 \mathrm{~min}$. The DNA samples were dissolved in $100 \mu \mathrm{L}$ of TE and kept at $4{ }^{\circ} \mathrm{C}$ overnight. The quality and concentration of the extracted DNA was detected using a spectrophotometer. Dilutions with TE were carried out and concentration was fixed at $100 \mathrm{ng} / \mu \mathrm{L}$.

Table 2. Name, origin, and seed type of faba bean genotypes used in the study.

\begin{tabular}{|c|c|c|c|c|c|c|c|}
\hline Entry No. & Entry name & Origin & Seed type & Entry No. & Entry name & Origin & Seed type \\
\hline 1 & Hassawil & KSA & Equine & 30 & Sakha 2 & Egypt & Major \\
\hline 2 & Hassawi2 & KSA & Equine & 31 & Sakha 3 & Egypt & Equine \\
\hline 3 & Hassawi3 & KSA & Equine & 32 & Giza 716 & Egypt & Major \\
\hline 4 & Goff1 & KSA & Equine & 33 & Giza 717 & Egypt & Equine \\
\hline 5 & T.W.(red seed) & KSA & Equine & 34 & Giza 843 & Egypt & Equine \\
\hline 6 & $\mathrm{H} 4$ & KSA & Equine & 35 & $1016 / 752 / 95$ & Egypt & Equine \\
\hline 7 & $\mathrm{H} 7$ & KSA & Equine & 36 & $987 / 255 / 95$ & Egypt & Major \\
\hline 8 & Line 9 & KSA & Equine & 37 & 989/306/95 & Egypt & Major \\
\hline 9 & Line 5 & KSA & Equine & 38 & $989 / 309 / 95$ & Egypt & Major \\
\hline 10 & Line 22 & KSA & Equine & 39 & Sakha 1 & Egypt & Equine \\
\hline 11 & Pop.6 & KSA & Equine & 40 & Sakha 4 & Egypt & Equine \\
\hline 12 & $\mathrm{H} 3$ & KSA & Equine & 41 & Giza 674 & Egypt & Equine \\
\hline 13 & H5 & KSA & Equine & 42 & Giza 714 & Egypt & Equine \\
\hline 14 & $\mathrm{H} 8$ & KSA & Equine & 43 & Cairo 7 & Egypt & Equine \\
\hline 15 & L. 4 & KSA & Equine & 44 & ILB 4338 & ICARDA & Equine \\
\hline 16 & Pop. 3 & KSA & Equine & 45 & ILB 4357 & ICARDA & Equine \\
\hline 17 & Pop. 4 & KSA & Equine & 46 & ILB 1814 & ICARDA & Major \\
\hline 18 & Giza 3 & KSA & Equine & 47 & Ahnacya 2 & ICARDA & Equine \\
\hline 19 & Giza 4 & Egypt & Equine & 48 & ILB 4347 & ICARDA & Equine \\
\hline 20 & Giza 40 & Egypt & Equine & 49 & ILB 4358 & ICARDA & Major \\
\hline 21 & Giza 402 & Egypt & Equine & 50 & Pakistani & Pakistan & Minor \\
\hline 22 & Giza 429 & Egypt & Equine & 51 & Luz & Spain & Major \\
\hline 23 & Giza 461 & Egypt & Equine & 52 & Aquadolce & Spain & Major \\
\hline 24 & Gizablanka & Egypt & Major & 53 & Kamline & Spain & Minor \\
\hline 25 & $1013 / 694 / 95$ & Egypt & Equine & 54 & Sudan & Sudan & Equine \\
\hline 26 & $1026 / 811 / 95$ & Egypt & Equine & 55 & Gazira 1 & Sudan & Major \\
\hline 27 & $985 / 252 / 95$ & Egypt & Equine & 56 & Gazira 2 & Sudan & Minor \\
\hline 28 & $989 / 303 / 95$ & Egypt & Equine & 57 & T.W. & Sudan & Equine \\
\hline 29 & Misr 1 & Egypt & Equine & 58 & Yamani (Large seed) & Yemen & Major \\
\hline
\end{tabular}

KSA, Kingdom of Saudi Arabia; ICARDA, International Center for Agricultural Research in Dry Areas. 


\subsection{SRAP-PCR}

Fifty five SRAP primer combinations ( 5 forward and 11 reverse) were tested for their ability to prime PCR amplification of 8 selected faba genotypes. Fourteen SRAP primer combinations that showed consistently reproducible polymorphisms were selected and used to analyze all of the 58 faba genotypes (Tables 1 and 3). The forward primers were 5' end labeled with FAM dye. The PCRs were performed in $20 \mu \mathrm{L}$ reaction volumes containing 1× GoTaq Green Master Mix (Cat. No. M7123, Promega Corporation, Madison, WI, USA), $0.1 \mu \mathrm{M}$ of each forward and reverse primer, $50 \mathrm{ng}$ DNA template, and nuclease-free water to $20 \mu \mathrm{L}$. The thermal cycler profile for PCR amplification was set on a TC-5000 thermal cycler (Bibby Scientific, Staffordshire, UK) as follows: denaturation at $94{ }^{\circ} \mathrm{C}$ for $5 \mathrm{~min}$, followed by five cycles of denaturing at $94{ }^{\circ} \mathrm{C}$ for $1 \mathrm{~min}$, annealing at $35{ }^{\circ} \mathrm{C}$ for $1 \mathrm{~min}$, and elongation at $72{ }^{\circ} \mathrm{C}$ for $1 \mathrm{~min}$. In the remaining 30 cycles, the annealing temperature was increased to $50{ }^{\circ} \mathrm{C}$ for $1 \mathrm{~min}$ followed by a final elongation step at $72{ }^{\circ} \mathrm{C}$ for $7 \mathrm{~min}$. For electrophoresis, $1 \mu \mathrm{L}$ of the PCR amplified product was mixed with $0.5 \mu \mathrm{L}$ of the GeneScan 500 LIZ size standard (Applied Biosystems P/N 4322682), and $8.5 \mu \mathrm{L}$ of Hi-Di Formamide (Applied Biosystems P/N 4311320). The mixture was denatured and loaded on the 16-capillary system of the Applied Biosystems 3130xl Genetic Analyzer. A 36-cm capillary array (Applied Biosystems P/N 4315931) and 3130 POP-7 polymer (Applied Biosystems P/N 4352759) were used.

Table 3. Name and sequence of the SRAP primer used in faba genotypes screening.

\begin{tabular}{cccc}
\hline Forward primers & $\mathbf{5}^{\prime} \rightarrow \mathbf{3}^{\prime}$ & Reverse primers & $\mathbf{5}^{\prime} \rightarrow \mathbf{3}^{\prime}$ \\
\hline ME1 & TGAGTCCAAACCGGAA & EM1 & GACTGCGTACGAATTAAT \\
ME2 & TGAGTCCAAACCGGAC & EM2 & GACTGCGTACGAATTTGC \\
ME3 & TGAGTCCAAACCGGAT & EM3 & GACTGCGTACGAATTGAC \\
ME4 & TGAGTCCAAACCGGAC & EM4 & GACTGCGTACGAATTTGA \\
\hline
\end{tabular}

\subsection{Data Scoring and Statistical Analysis}

SRAP fragment analysis was performed with the GeneMapper Analysis Software v3.7 (Applied Biosystems: Foster City, CA, USA), and the data were assembled in binary format (allele presence (1) or (0) for absence). The threshold for fragment calling was set at 200 relative fluorescence units (rfu) [63], so that any peaks at $200 \mathrm{rfu}$ or higher was assigned a 1 and those that were lower were assigned a 0. Fragment analysis was carried out for fragment sizes in the range of 100-500 bp. Fragments that were amplified in less than three genotypes were eliminated from the analysis. The polymorphism information content (PIC) for each primer was calculated to estimate its allelic variation according to the formula

$$
\mathrm{PIC}=1-\sum_{j=1}^{n} P_{i j}^{2}
$$

Where $P_{\mathrm{ij}}$ is the frequency of the $i^{\text {th }}$ allele for marker $\mathrm{j}$ and the summation extends over $n$ alleles, calculated for each SRAP marker [64]. Data generated from SRAP analysis were analyzed using Jaccard similarity coefficient [65]. These similarity coefficients were used to construct dendrogram using the unweighted pair group method with arithmetic average (UPGMA) employing 
the SAHN (sequential, agglomerative, hierarchical, and nested clustering) from the NTSYSpc (version 2.10) program [66].

\section{Conclusions}

The rich polymorphism rate $(100 \%)$ and low genetic similarity $(0.21)$ indicated the high genetic diversity and broad genetic basis of our collection. The large number of polymorphic amplified fragments produced in this study (1036), with an average of 74 fragments per primer pair indicates that this system is a reliable and powerful tool to evaluate genetic polymorphisms and relationships among faba bean genotypes. Such information will be useful to determine optimal breeding strategies, and to allow continued progress in faba bean breeding. Diverse genetic backgrounds among parental lines provide a large supply for allelic variations that can be used to develop new favorable gene combinations in faba breeding programs.

\section{Acknowledgements}

The authors wish to express their thanks and gratitude to the Center of Excellence of Biotechnology Research, King Saud University and Ministry of Higher Education for the funding the project No. CBER 2-07.

\section{References}

1. Ellwood, S.R.; Phan, H.T.; Jordan, M.; Hane, J.; Torres, A.M.; Avila, C.M.; Cruz-Izquierdo, S.; Oliver, R.P. Construction of a comparative genetic map in faba bean (Vicia faba L.); Conservation of genome structure with Lens culinaris. BMC Genomics 2008, 9, 380.

2. Rispail, N.; Kalo, P.; Kiss, G.B.; Ellis, T.H.; Gallardo, K.; Thompson, R.D.; Prats, E.; Larrainzar, E.; Ladrera, R.; Gonzalez, E.M.; Esther, M.; et al. Model legumes contribute to faba bean breeding. Field Crops Res. 2010, 115, 253-269.

3. Link, W.; Dixkens, C.; Singh, M.; Schwall, M.; Melchinger, A.E. Genetic diversity in European and Mediterranean faba bean germplasm revealed by RAPD markers. Theor. Appl. Genet. 1995, 90, 27-32.

4. Avila, C.M.; Sillero, J.C.; Rubiales, D.; Moreno, M.T.; Torres, A.M. Identification of RAPD markers linked to the Uvf-1 gene conferring hypersensitive resistance against rust (Uromyces viciae-fabae) in Vicia faba L. Theor. Appl. Genet. 2003, 107, 353-358.

5. Zeid, M.A.; Schön, C.C.; Link, W. Genetic diversity in recent elite faba bean lines using AFLP markers. Theor. Appl. Genet. 2003, 107, 1304-1314.

6. Roman, B.L.; Satovic, Z.; Pozarkova, D.D.; Macas, J.; Dolezel, J.; Cubero, J.I.; Torres, A.M. Development of a composite map in Vicia faba L., breeding applications and future prospects. Theor. Appl. Genet. 2004, 108, 1079-1088.

7. Gutierrez, N.; Avila, C.M.; Rodriguez-Suarez, C.; Moreno, M.T.; Torres, A.M. Development of SCAR markers linked to a gene controlling absence of tannins in faba bean. Mol. Breed. 2007, 19, 305-314. 
8. Van de Ven, W.T.; Powell, W.; Ramsay, G.; Waugh, R. Restriction fragment length polymorphisms as genetic markers in Vicia. Heredity 1990, 65, 329-342.

9. Torres, A.M.; Weeden, N.F.; Martin, A. Linkage among isozyme, RFLP and RAPD markers in Vicia faba L. Theor. Appl. Genet. 1993, 85, 937-945.

10. Alghamdi, S.S. Varietal identification and genetic purity assessment of F1 hybrid seeds using RAPD markers in faba bean (Vicia faba L.). Acta Hortic. 2009, 829, 269-274.

11. Zong, X.; Liu, X.Z.; Guan, J.P.; Wang, S.; Liu, Q.; Paull, J.G.; Redden, R.J. Molecular variation among Chinese and global winter faba bean germplasm. Theor. Appl. Genet. 2009, 118, 971-978.

12. Zong, X.; Ren, J.; Guan, J.P.; Wang, S.; Liu, Q.; Paull, J.G.; Redden, R.J. Molecular variation among Chinese and global germplasm in spring faba bean areas. Plant Breed. 2010, 129, 508-513.

13. Terzopoulos, P.J.; Bebeli, P.J. Genetic diversity analysis of Mediterranean faba bean (Vicia faba L.) with ISSR markers. Field Crops Res. 2008, 108, 39-44.

14. Alghamdi, S.S.; Al-Faifi, S.A.; Migdadi, H.M.; Ammar, M.H.; Siddique, K.M. Inter-simple sequence repeat (ISSR)-based diversity assessment among faba bean genotypes. Crop Pasture Sci. 2011, 62, 755-760.

15. Duc, G.; Bao, S.Y.; Baum, M.; Redden, B.; Sadiki, M.; Suso, M.J.; Vishniakova, M.; Zong, X.X. Diversity maintenance and use of Vicia faba L. genetic resources. Field Crops Res. 2010, 115, 270-278.

16. Kwon, S.J.; Jinguo, H.; Clarice, J.C. Genetic diversity and relationship among faba bean (Vicia faba L.) germplasm entries as revealed by TRAP markers. Plant Genet. Resour. 2010, 8, 204-213.

17. Van de Ven, W.T.; Duncan, N.; Ramsay, G.; Phillips, M.S.; Powell, W.; Waugh, R. Taxonomic relationships between $\mathrm{V}$. faba L. and its relatives based on nuclear and mitochondrial RFLPs and PCR analysis. Theor. Appl. Genet. 1993, 86, 71-80.

18. Shiran, B.; Mashayekh, A.M. Evaluation of the chlroplast DNA among Vicia faba L. germplasm using restriction-site analysis. Iranian J. Sci. Tech. Transac. A 2004, 28, 51-55.

19. Flamand, M.C.; Goblet, J.P.; Duc, G.; Briquet, M.; Boutry, M. Sequence and transcription analysis of mitochondrial plasmids isolated from cytoplasmic male-sterile lines of Vicia faba L. Plant Mol. Biol. 1992, 19, 913-923.

20. Flamand, M.C.; Due, G.; Goblet, J.P.; Hong, L.; Louis, O.; Briquet, M.; Boutry, M. Variant mitochondrial plasmids of broad bean arose by recombination and are controlled by the nuclear genome. Nucl. Acids Res. 1993, 21, 5468-5473.

21. Sanz, A.M.; Gonzalez, S.G.; Syed, N.H.; Suso, M.J.; Saldaña, C.C.; Flavell, A.J. Genetic diversity analysis in Vicia species using retrotransposon-based SSAP markers. Mol. Genet. Genom. 2007, 278,433-441.

22. Li, G.Y.; Quiros, C.F. Sequence-related amplified polymorphism (SRAP), a new marker system based on a simple PCR reaction, its application to mapping and gene tagging in Brassica. Theor. Appl. Genet. 2001, 103, 455-461.

23. Rana, M.; Singh, S.P.; Bhat, K. Fingerprinting Indian lentil (Lens culinaris ssp. culinaris Medik.) Cultivars and Landraces for Diversity Analysis Using Sequence-Related Amplified Polymorphism (SRAP) Markers. In Proceedings of Fourth International Food and Legumes Research Conference, New Delhi, India, 2009; pp. 617-624. 
24. Vandemark, G.J.; Ariss, J.J.; Bauchan, G.A.; Larsen, R.C.; Hughes, T.J. Estimating genetic relationships among historical sources of alfalfa germplasm and selected cultivars with sequence related amplified polymorphisms. Euphytica 2006, 152, 9-16.

25. Ariss, J.J.; Vandemark, G.J. Assessment of genetic diversity among nondormant and semidormant alfalfa populations using sequence-related amplified polymorphisms. Crop Sci. 2007, 47, 2274-2284.

26. Castonguay, Y.; Cloutier, J.; Bertrand, A.; Michaud, R.; Laberge, S. SRAP polymorphisms associated with superior freezing tolerance in alfalfa (Medicago sativa spp. sativa). Theor. Appl. Genet. 2010, 120, 1611-1619.

27. Esposito, M.A.; Martin, E.A.; Craverom, V.P.; Cointry, E. Characterization of pea accessions by SRAP's markers. Sci. Hort. 2007, 113, 329-335.

28. Al-Ali, A.A.; Alghamdi, S.S.; Alfifi, S.A. Evaluation of Morphological and Molecular Variations among Faba Bean Genotypes Differing in Their Drought Tolerance Levels. In Proceedings of 5th International Food Legumes Research Conference (IFLRC V), Antalya, Turkey, 26-30 April 2010.

29. Gong, Y.M.; Xu, S.C.; Mao, W.H.; Li, Z.Y.; Hu, Q.Z.; Zhang, G.W.; Ding, J. Genetic diversity analysis of faba bean (Vicia faba L.) based on EST-SSR markers. Agric. Sci. China 2010, 10, 838-844.

30. Požárková, D.; Koblížková, A.; Román, B.; Torres, A.M.; Lucretti, S.; Lysak, M.; Doležel, J.; Macas, J. Development and characterization of microsatellite markers from chromosome 1-specific DNA libraries of Vicia faba L. Biol. Plantarum 2002, 45, 337-345.

31. Zeid, M.A.; Mitchell, S.E.; Link, W.; Carter, M.; Nawar, A.I.; Fulton, T.; Kresovich, S. Simple sequence repeats (SSRs) in faba bean, new loci from Orobanche-resistant cultivar 'Giza 402'. Plant Breed. 2009, 128, 149-155.

32. Torres, A.M.; Avila, C.M.; Gutierrez, N.; Palomino, C.; Moreno, M.T.; Cubero, J.I. Marker-assisted selection in faba bean (Vicia faba L.). Field Crops Res. 2010, 115, 243-252.

33. Dudley, J.W. Comparison of Genetic Distance Estimators Using Molecular Marker Data. In Proceedings of the Symposium on Analysis of Molecular Marker Data, Corvallis, OR, USA, 5-6 August 1994; pp. 3-7.

34. Pejic, I.; Ajmone-Marsan, P.; Morgante, M.; Kozumplick, V.; Castiglioni, P.; Taramino, G.; Motto, M. Comparative analysis of genetic similarity among maize inbred lines detected by RFLPs, RAPDs, SSRs and AFLPs. Theor. Appl. Genet. 1998, 97, 1248-1255.

35. Ferriol, M.; Pico, B.; Fernandez, P.; Cordova, D.; Nuez, F. Molecular diversity of a germplasm collection of squash (Cucurbita moschata) determined by SRAP and AFLP markers. Crop Sci. 2004, 44, 653-664.

36. Budak, H.; Shearman, R.C.; Parmaksiz, I.; Gaussoin, R.E.; Riordan, T.P.; Dweikat, I. Molecular characterization of buffalograss germplasm using sequence-related amplified polymorphism markers. Theor. Appl. Genet. 2004, 108, 328-334.

37. Suman, A.; Kimbeng, C.A.; Edmé, S.J.; Veremis, J.C. Sequence-related amplified polymorphism (SRAP) markers for assessing genetic relationships and diversity in sugarcane germplasm collections. Plant Genet. Resour. 2008, 6, 222-231.

38. Dong, P.; Wei, Y.M.; Chen, G.Y.; Li, W.H.; Wang, J.R.; Nevo, E.; Zheng, Y.L. Sequence-related amplified polymorphism (SRAP) of wild emmer wheat (Triticum dicoccoides) in Israel and its ecological association. Biochem. Syst. Ecol. 2010, 38, 1-11. 
39. Zhang, Y.N.; Sun, S.J.; Zhang, X.C.; Wang, L.S.; Che, Z. Analysis on genetic diversity and genetic basis of the main sesame cultivars released in China. Agric. Sci. China 2011, 10, 509-518.

40. Zhang, Y.N.; Zhang, X.C.; Hua, W.; Wang, L.S.; Che, Z. Analysis of genetic diversity among indigenous landraces from sesame (Sesamum indicum L.) core collection in China as revealed by SRAP and SSR markers. Genes Genom. 2010, 32, 207-215.

41. Peng, S.; Feng, N.; Guo, M.; Chen, G.Y.; Guo, Q.S. Genetic variation of Carthamus tinctorius L. and related species revealed by SRAP analysis. Biochem. Syst. Ecol. 2008, 36, 531-538.

42. Talebi, M.B.; Mokhtari, N.; Rahimmalek, M.; Sahhafi, S. Molecular characterization of Carthamus tinctorius and $C$. oxyacanthus germplasm using sequence related amplified polymorphism (SRAP) markers. Plant Omics J. 2012, 5, 136-142.

43. Rana, M.; Arora, K.; Singh, S.P.; Singh, A.K. Multi-locus DNA fingerprinting and genetic diversity in jute (Corchorus spp.) based on sequence-related amplified polymorphism. J. Plant Biochem. Biotechnol. 2012, doi:10.1007/s13562-012-0104-7.

44. Talebi, M.B.; Hajiahmadi, Z.; Rahimmalek, M. Genetic diversity and population structure of four Iranian alfalfa populations revealed by sequence-related amplified polymorphism (SRAP) Markers. J. Crop Sci. Biotech. 2011, 14, 173-178.

45. Mishra, M.K.; Suresh, N.; Bhat, A.M.; Suryaprakash, N.; Kumar, S.S.; Kumar, A.; Jayarama. Genetic molecular analysis of Coffea arabica (Rubiaceae) hybrids using SRAP markers. Rev. Biol. Trop. 2011, 59, 607-617.

46. Youssef, M.; James, A.C.; Rivera-Madrid, R.; Ortiz, R.; Escobedo-Gracia Medrano, R.M. Musa genetic diversity revealed by SRAP and AFLP. Mol. Biotechnol. 2011, 47, 189-199.

47. Hao, Q.; Liu, Z.A.; Shu, Q.Y.; Zhang, R.; Rick, J.D.; Wang, L.S. Studies on Paeonia cultivars and hybrids identification based on SRAP analysis. Hereditas 2008, 145, 38-47.

48. Lan, Q.I.; Wang, W.Q.; Zhang, Z.W.; Ye, J.Q.; Li, K.M. DNA fingerprints of 18 cassava varieties based on sequence-related amplified polymorphism markers. Acta Agron. Sin. 2010, 36, 1642-1648.

49. Li, H.; Chen, H.; Zhuang, T.; Chen, J. Analysis of genetic variation in eggplant and related Solanum species using sequence-related amplified polymorphism markers. Sci. Hort. 2010, 125, $19-24$.

50. Wu, Y.G.; Guo, Q.S.; He, J.C.; Lin, Y.F.; Luo, L.J.; Liu, G.D. Genetic diversity analysis among and within populations of Pogostemon cablin from China with ISSR and SRAP markers. Biochem. Syst. Ecol. 2010, 38, 63-72.

51. Wu, X.Y.; Chen, B.Y.; Lu, G.; Wang, H.Z.; Xu, K.; Guizhan, G.; Song, Y. Genetic diversity in oil and vegetable mustard (Brassica juncea) landraces revealed by SRAP markers. Genet. Resour. Crop Evol. 2009, 56, 1011-1022.

52. Ferriol, M.; Pico, B.; Nuez, F. Genetic diversity of a germplasm collection of Cucurbita pepo using SRAP and AFLP markers. Theor. Appl. Genet. 2003, 107, 271-282.

53. Gulsen, O.; Karagul, S.; Abak, K. Diversity and relationships among Turkish okra germplasm by SRAP and phenotypic marker polymorphism. Biologia 2007, 62, 41-45.

54. Suso, M.J.; Moreno, M.T. Variation in outcrossing rate and genetic structure on six culitvars of Vicia faba L. as affected by geographic location and year. Plant Breed. 1999, 118, 347-350.

55. Suso, M.J.; Pierre, J.; Moreno, M.T.; Esnault, R.; Le Guen, J. Variation in outcrossing levels in faba bean cultivars, role of ecological factors. J. Agric. Sci. 2001, 136, 399-405. 
56. Suso, M.J.; Gilsanz, S.; Duc, G.; Marget, P.; Moreno, M.T. Germplasm management of faba bean (Vicia faba L.), monitoring intercrossing between accessions with interplot barriers. Genet. Resour. Crop Evol. 2006, 53, 1427-1439.

57. Suso, M.J.; Nadal, S.M.; Roman, B.L.; Gilsanz, S. Vicia faba L. germplasm multiplication, floral traits associated with pollen-mediated gene flow under diverse between-plot isolation strategies. Ann. Appl. Biol. 2008, 152, 201-208.

58. Gresta, F.; Avola, G.; Albertini, E.; Raggi, L.; Abbate, V. A study of variability in the Sicilian faba bean landrace 'Larga di Leonforte'. Genet. Resour. Crop Evol. 2010, 57, 523-531.

59. Schill, B.; Melchinger, A.E.; Gumber, R.K.; Link, W. Comparison of intra- and inter-pool crosses in faba bean (Vicia faba L.). II. Genetic effects estimated from generation means in Mediterranean and German environments. Plant Breed. 1998, 117, 351-359.

60. Cubero, J.I. Faba Bean Improvement; Hawtin, G., webb, C., Eds.; Martinus nijhoff: The Hague, The Netherlands, 1982; pp. 91-108.

61. Hanelt, P. Die intraspezifische Variabilität von Vicia faba L. und ihre Gliederung. Kulturpflanze 1972, 20, 75-128.

62. Hoelzel, A.R. Molecular Genetic Analysis of Populations, Apractical Approach, 2nd ed; Oxford University Press: NewYork, NY, USA, 1998.

63. Wooten, J.A.; Tolley-Jordan, L.R. Validation of phylogenetic signals in amplified fragment length data:testing the utility and reliability in closely related taxa. BMC Res. Notes 2009, 2, 26.

64. Anderson, J.A.; Churchill, G.A.; Autrique, J.E.; Tanksley, S.D.; Sorrells, M.E. Optimizing parental selection for genetic linkage maps. Genome 1993, 36, 181-186.

65. Jaccard, P. Nouvelles recherches sur la distribution florale. Bull. Soc. Vaud. Sci. Nat. 1908, 44, 223-270.

66. Rohlf, F.J. Ntsys-pc, Numerical Taxonomy and Multivariate Analysis System, Version 2.2; Exeter Publishing Ltd.: New York, NY, USA, 2005.

(C) 2012 by the authors; licensee MDPI, Basel, Switzerland. This article is an open access article distributed under the terms and conditions of the Creative Commons Attribution license (http://creativecommons.org/licenses/by/3.0/). 